\title{
Observation of Multi-Scale Structure for a Creep-Fatigued Ferritic 12Cr-2W Steel*
}

\author{
Masao Hayakawa, Koji Yamaguchi, Megumi Kimura and Kazuo Kobayashi \\ Materials Information Technology Station, National Institute for Materials Science (MITS/NIMS), Tsukuba 305-0047, Japan
}

Microstructural analyses by field emission-type scanning electron microscopy (FE-SEM) and transmission electron microscopy (TEM) were performed on a ferritic heat-resisting steel that contained 12 mass $\%$ chromium and 2 mass $\%$ tungsten to characterize its multi-scale structure, consisting of prior austenite grains, packets, blocks, subgrains and precipitates. The size distributions of the blocks, subgrains and precipitates were quantitatively evaluated before and after a creep-fatigue test to relate them to their creep-fatigue property. Our results showed that the occupancy of precipitates on prior austenite grain boundaries increased markedly and subgrains became coarse during the creep-fatigue test, while the block size did not change. It is suggested that the growth of grain boundary precipitates and coarse subgrains plays an important role in the intergranular fracture mechanism caused by creep-fatigue.

(Received August 24, 2004; Accepted October 12, 2004)

Keywords: ferritic chromium-tungsten steel, tempered martensite, grain boundary precipitate, block, subgrain, creep-fatigue

\section{Introduction}

Ferritic heat-resisting steel that contains 12 mass $\%$ chromium and 2 mass $\%$ tungsten $(12 \mathrm{Cr}-2 \mathrm{~W})$ has relatively high creep fracture strength and a small coefficient of thermal expansion. This steel has recently been developed and is in use as a new material in supercritical pressure power plants. ${ }^{1,2)}$ To predict the deterioration of this steel, microstructural factors that determine its high-temperature mechanical properties need to be quantitatively evaluated.

Optical microscopic observations have revealed that ferritic $12 \mathrm{Cr}-2 \mathrm{~W}$ steel has a tempered martensite structure (Fig. 1(a)). ${ }^{3-5)}$ As shown in the schematic diagram in Fig. 1(b), the multi-scale structure consist, in descending order of size, of prior austenite $(\gamma)$ grains, packets, blocks and subgrains. $\left.{ }^{6}\right)$ Several studies have been conducted on the multi-scale structure of ferritic steels, ${ }^{7)}$ but most other studies have focused on changes in the distribution of precipitates and on transmission electron microscopic (TEM) observations. $^{8-11)}$

The authors observed the electropolished surface of a tempered martensite structure of low-alloy medium carbon steel under an atomic force microscope (AFM). ${ }^{12}$ ) This method enables photographs of prior $\gamma$ grains, packets and blocks to be easily taken. Electropolishing produces small differences in level of approximately $10 \mathrm{~nm}$ between blocks that result from differences in crystal orientation at the specimen's surface. AFM, which has high vertical resolution, can visualize these minute changes in level. The distribution of carbide precipitates in grain interiors and grain boundaries was quantitatively analyzed in terms of both number and size by specifying the locations of prior $\gamma$ grain boundaries in a large visual field. ${ }^{13-15)}$

The authors also applied microstructural analytical methods to ferritic heat-resisting steels that were originally developed for carbon steels. Electropolished surfaces of 9 to 12 mass\% Cr ferritic steel were observed under a field

*This Paper was Originally Published in Japanese in J. Japan Inst. Metals 68 (2004) 216-222. (a)
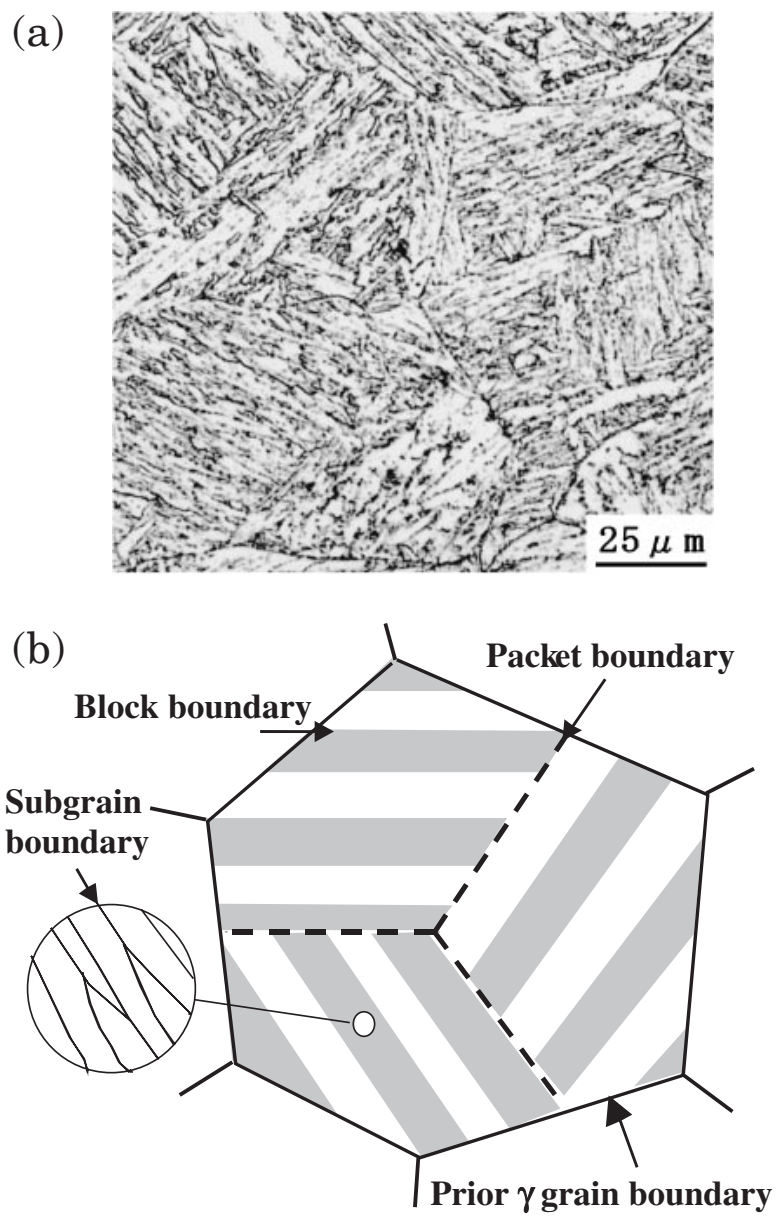

Fig. 1 Optical image and schematic illustration of the microstructure factors within a prior austenite $(\gamma)$ grain are shown in (a) and (b), respectively.

emission-type scanning electron microscope (FE-SEM), and thin films of these specimens were observed under a TEM. ${ }^{6}$ ) FE-SEM, which has a resolution one order higher than that of an ordinary SEM, was used instead of an AFM. The analysis revealed that there is a correlation between the distribution of 
Table 1 Chemical composition and thermal processing are shown in (a) and (b), respectively.

(a) Chemical composition (mass \%) of the material used.

\begin{tabular}{llcccccccccccccccc}
\hline Material & Form & $\mathrm{C}$ & $\mathrm{Si}$ & $\mathrm{Mn}$ & $\mathrm{Cu}$ & $\mathrm{Ni}$ & $\mathrm{Cr}$ & $\mathrm{W}$ & $\mathrm{Mo}$ & $\mathrm{V}$ & $\mathrm{Nb}$ & $\mathrm{N}$ & $\mathrm{Fe}$ \\
\hline $12 \mathrm{Cr}-2 \mathrm{~W}$ & Pipe & 0.14 & 0.26 & 0.65 & 0.74 & 0.4 & 11.03 & 1.95 & 0.29 & 0.2 & 0.07 & 0.06 & $\mathrm{Bal}$. \\
\hline
\end{tabular}

(b) Thermal processing of the material used.

\begin{tabular}{ccccc}
\hline Material & Form & Normalizing & & Tempering \\
\hline $12 \mathrm{Cr}-2 \mathrm{~W}$ & Pipe & $1323 \mathrm{~K}, 3.6 \mathrm{ks}$ & Air cooled & $1053 \mathrm{~K}, 21.6 \mathrm{ks}$ \\
\hline
\end{tabular}

precipitates on prior $\gamma$ grain boundaries and creep-fatigue life.

In this study, precipitates, blocks and subgrains of ferritic heat-resisting $12 \mathrm{Cr}-2 \mathrm{~W}$ steel were quantified based on the microstructural observation results reported in the previous paper.6) In particular, we focused on differences in the distributions of precipitates before and after creep-fatigue testing. This study also proposes a simple method for quantifying precipitate distribution, which reflects changes in the microstructure caused by creep-fatigue.

\section{Experimental Procedure}

\subsection{Materials}

The specimen was $12 \mathrm{Cr}-2 \mathrm{~W}$ steel, excised from a thickwalled pipe (ASTM-SA355-P122) that had been processed for use as a main steam pipe in a fossil fuel power plant. The chemical compositions and thermal treatments are shown in Table 1. The material had been normalized at $1323 \mathrm{~K}$ for $3.6 \mathrm{ks}$ and cooled in air. It was then tempered at $1053 \mathrm{~K}$ for $21.6 \mathrm{ks}$. Most prior $\gamma$ grains were approximately 150 to $200 \mu \mathrm{m}$ in diameter.

The data on tensile tests, creep rupture tests and creepfatigue tests are reported in previous papers. ${ }^{3-5)}$ The creepfatigue tests were conducted at $923 \mathrm{~K}$. Trapezoidal waves were used to apply strain. The total stain range of the waves was $1.0 \%$. The duration of $1.0 \%$ strain was $10.8 \mathrm{ks}$. The transition strain rate was $5 \times 10^{-4} / \mathrm{s}$. The resultant cycles for creep-fatigue rupture (creep-fatigue life) were 309 cycles (total duration: $3349 \mathrm{ks}$ ). Fractures originated at prior $\gamma$ grain boundaries.

\subsection{Specimen preparation}

Thin sections of $7 \mathrm{~mm}$ in length, $5 \mathrm{~mm}$ in width and $1 \mathrm{~mm}$ in thickness were excised before and after the creep-fatigue test (after fracture) along the load direction of the parallel gauge. The surfaces were buff-polished using diamond particles $1 \mu \mathrm{m}$ in diameter, and were finished by electropolishing. Electrolyte $\left(1000 \mathrm{~cm}^{3}\right)$ was prepared by mixing $80 \mathrm{~cm}^{3}$ perchloric acid, $700 \mathrm{~cm}^{3}$ ethanol, $100 \mathrm{~cm}^{3}$ butoxyethanol and $120 \mathrm{~cm}^{3}$ distilled water. A voltage of $40 \mathrm{~V}$ was applied for $10 \mathrm{~s}$. Since the rate of electropolishing depends on precipitate phase and crystal orientation, this treatment causes slight unevenness to be formed on the surface. ${ }^{12,13)}$ FE-SEM can detect minute changes in level that identify the microstructure.

For TEM observation, thin films of $4 \mathrm{~mm}$ in length and width and $0.5 \mathrm{~mm}$ in thickness were excised before and after the creep-fatigue test perpendicularly to the load direction of the parallel gauge. The specimens were mechanically polished up to a thickness of $70 \mu \mathrm{m}$, and then electropolished using the Twin-jet method and a solvent containing $5 \mathrm{vol} \%$ perchloric acid and 95 vol\% acetic acid.

\section{Results and Discussion}

\subsection{Tempered martensite microstructure}

Figure 2 shows FE-SEM images before the creep-fatigue test. The black and white contrast in the images shows the level differences on the electropolished surface. These differences in level are attributable to differences in the rate of electropolishing, which in turn depend on the crystal orientation and phase at the surface. The smallest crystal
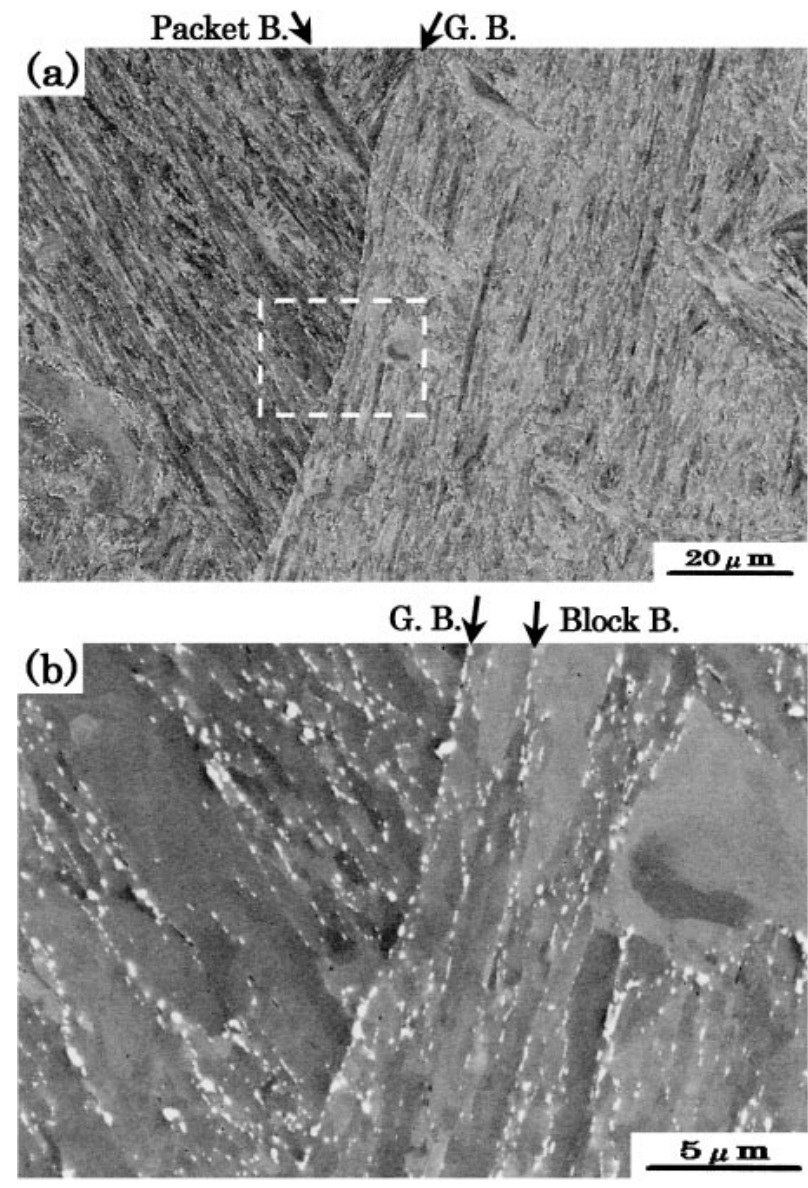

Fig. 2 FE-scanning electron images of the specimen before the creepfatigue testing. The larger magnification image of the area shown with white doted lines in (a) is shown in (b). Typical prior austenite grain boundary (G.B.), block and packet boundary (Block B. and Packet B.) are indicated by arrows. 

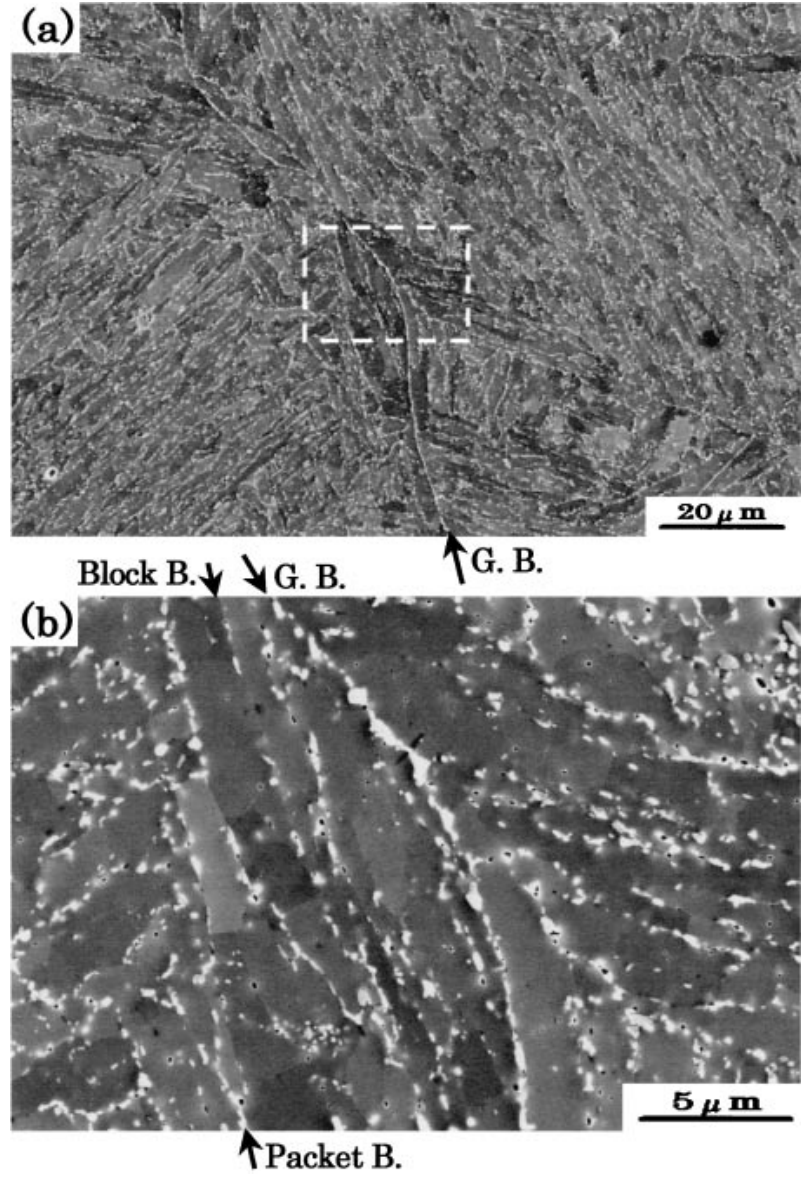

Fig. 3 FE-scanning electron images of the specimen after the creep-fatigue testing. The larger magnification image of the area shown with white doted lines in (a) is shown in (b). Typical prior austenite grain boundary (G.B.), block and packet boundary (Block B. and Packet B.) are indicated by arrows.

phase that has high misorientation angle boundary is a block. ${ }^{16-18)}$ The black and white contrast identifies blocks. Packets are where blocks are arranged in parallel alignment. Prior $\gamma$ grains contain several packets. Prior $\gamma$ grain boundaries are longer than the packet boundaries and can be separately identified.

Precipitate particles are shown as white spots extruding from the base metal. These were dense on high misorientation angle boundaries such as block boundaries, packet boundaries and prior $\gamma$ grain boundaries.

Figure 3 shows FE-SEM images of the electropolished surface after the creep-fatigue test. As before the test, blocks, packets and prior $\gamma$ grains are observed on the martensite base. The precipitate particles are larger than those before the test. Precipitates on the boundaries are also denser. On prior $\gamma$ grain boundaries, particularly coarse precipitations are observed where precipitates were dense and formed a filmlike cover.

Figures 4(a) and (b), respectively, show TEM images of microstructures before and after the test. Similarly contrasted regions can be seen in the images. These regions are subgrains: crystal units with a low misorientation angle boundary. In a TEM image, to identify a block, which is a group of subgrains, the crystal orientations of every subgrain
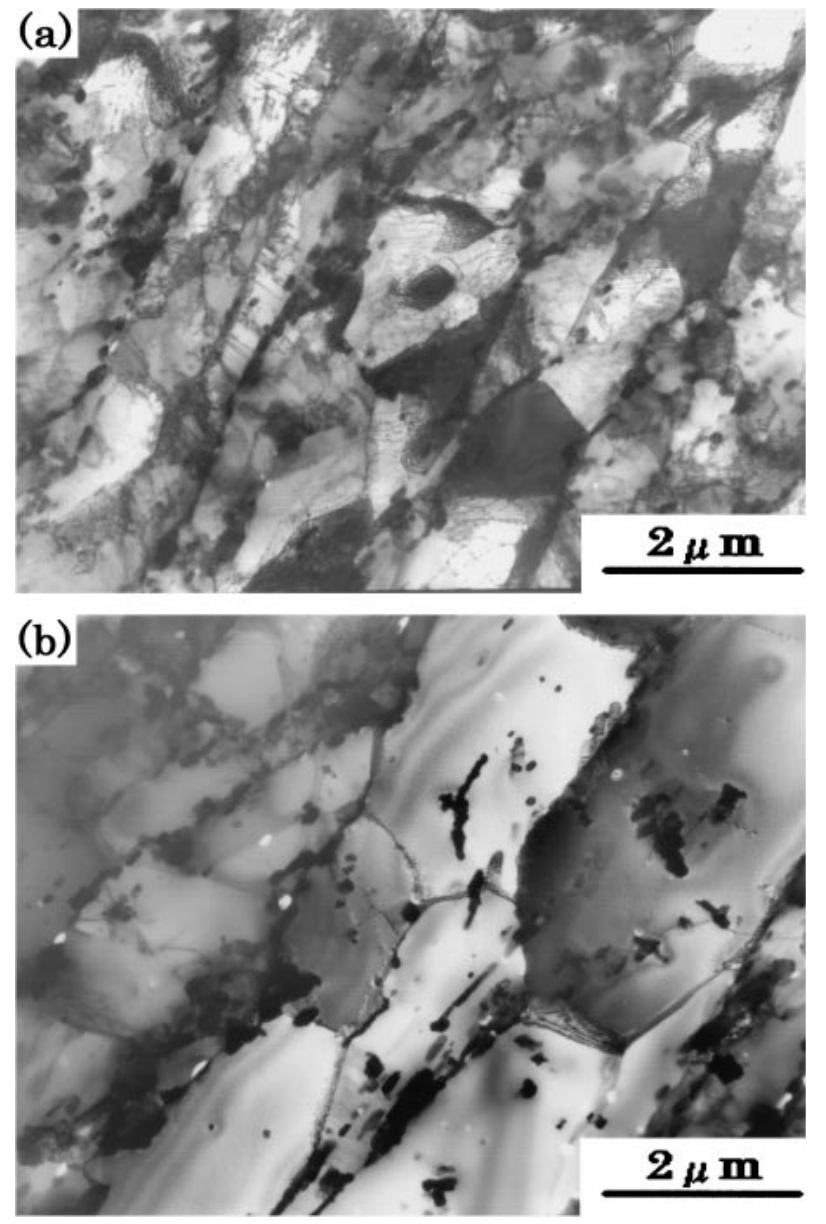

Fig. 4 Transmission electron images of the specimens before and after the creep-fatigue testing are shown in (a) and (b), respectively.

must be identified. Subgrains after the creep-fatigue test are notably coarser than those before the test. In Fig. 4(a), the dislocation density within subgrains was high, and dislocations were difficult to distinguish from precipitates. On the other hand, in Fig. 4(b), the dislocation density was low, allowing precipitates to be easily distinguished from dislocations. In spite of this, dislocations and precipitates near boundaries were difficult to be identified separately.

These observations show that FE-SEM and TEM can be combined to quantitatively analyze the multi-scale structure of $12 \mathrm{Cr}-2 \mathrm{~W}$ steel, which comprises structural factors of varying sizes. FE-SEM images are suitable for estimating the sizes of precipitate particles and blocks. TEM images are suitable for estimating the size of subgrains.

\subsection{Changes in microstructure caused by creep-fatigue 3.2.1 Distribution of precipitates}

Fractures originated at prior $\gamma$ grain boundaries during the creep-fatigue test. Precipitates on boundaries have been shown to play important roles in intergranular fracture mechanisms of tempered martensitic steels. ${ }^{14,15,19-21)}$ For this reason, the authors quantified precipitate distribution separately for the entire microstructure and prior $\gamma$ grain boundaries (intergranular).

Measuring the sizes of all precipitate particles on FE-SEM images is unrealistic, since they are too numerous. The size of 


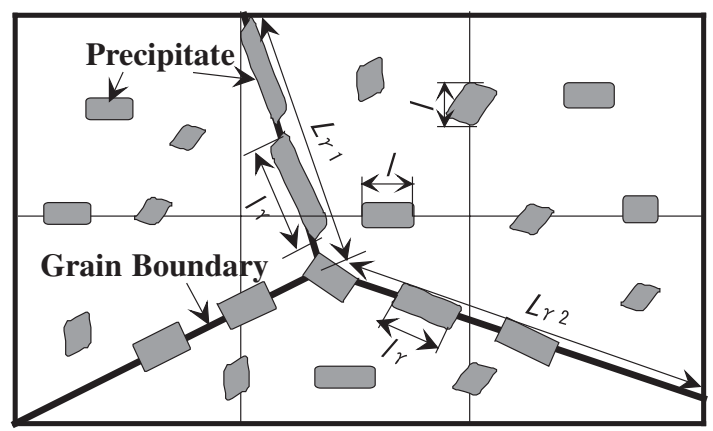

Fig. 5 Schematic drawing of the intra- and inter-granular precipitates.

precipitates on the entire microstructure was estimated by applying the cutting method $^{22)}$ used to determine nominal grain size. As schematically shown in Fig. 5, each FE-SEM image $(\times 5000)$ was divided into six equal sections by drawing two vertical lines and one horizontal line. (The length of each segment line is $L$.) These segment lines mainly cross precipitates inner prior $\gamma$ grains, so the entire microstructure approximately means inner prior $\gamma$ grains (intragranular). The sum of the length of precipitates on the lines (referred to here as the "nominal precipitate particle length $l$ " for convenience) and the occupancy on the lines (referred to here as the "mean volumetric occupancy $f$ " for convenience) were calculated as $f=\Sigma(l / L) \times 100(\%)$. If the segment lines are long enough compared to precipitate size, $f$ reflects the mean volumetric occupancy of the precipitate.

The occupancy of prior $\gamma$ grain boundary by precipitates (referred to here as "grain-boundary occupancy") $f_{\gamma}=$ $\Sigma\left(l_{\gamma} / L_{\gamma}\right) \times 100(\%)$ was determined for each visual field of FE-SEM image $(\times 5000)$, where $l_{\gamma}$ is the length of a precipitate particle along the direction of the prior $\gamma$ grain boundary (referred to here as the "grain-boundary precipitate length" for convenience) and $L_{\gamma}$ is the length of the grain boundary. The grain boundary occupancy is also the boundary volumetric occupancy, assuming the width of precipitates on the grain boundaries to be uniform.

Figure 6 shows histograms of mean volumetric occupancy and grain-boundary occupancy for the specimens before and after the creep-fatigue test. The values were determined for each FE-SEM visual field $(\times 5000)$. The mean volumetric occupancy for all visual fields before the test was $6.2 \%$. The mean grain-boundary occupancy was $52 \%$. On the other hand, in the fractured specimens, the mean volumetric occupancy for all visual fields was $9.4 \%$. The mean grainboundary occupancy was $69 \%$.

Figure 7 shows histograms of nominal precipitate particle length $l$ and grain-boundary precipitate particle length $l_{\gamma}$ of the specimens before and after the creep-fatigue test. Before the test, the mean nominal precipitate length was $123 \mathrm{~nm}$, and the mean grain-boundary precipitate length was $273 \mathrm{~nm}$. In the fractured specimens, or after the test, the mean nominal precipitate length was $166 \mathrm{~nm}$. The mean grain-boundary precipitate length was $309 \mathrm{~nm}$.

Based on the results, the relationship between volumetric occupancy and precipitate length was analyzed. Figure 8 is a plot of mean volumetric occupancy and grain-boundary (volumetric) occupancy against mean nominal precipitate length and grain-boundary precipitate length, respectively. The Figure shows the results before and after the creepfatigue test. The relationship between mean volumetric occupancy and nominal precipitate length shows the condition of the entire specimen. The relationship was linear before and after the test, showing that they were mutually proportional. The relationship between the grain-boundary occupancy and grain-boundary precipitate length was also linear, showing that they were similarly mutually proportional. However, in the fractured specimens, the increase in grain-boundary occupancy was greater than the increase in precipitate length.

Our results show that changes in precipitate distribution are more notable on prior $\gamma$ grain boundaries than in grain interiors. Therefore, grain-boundary occupancy can be used as an index of damage to the microstructure by creep-fatigue that originates at prior $\gamma$ grain boundaries.

\subsubsection{Blocks}

Whether the mechanical strength of tempered martensitic steels is determined by blocks has been much discussed. ${ }^{17,18,23,24)}$ The block widths were measured before and after the creep-fatigue test from FE-SEM images, and the distributions of the measurements were compared. High misorientation angle boundaries, such as prior $\gamma$ grains, packets and block boundaries, act as preferential sites for precipitation, and are thus densely covered by precipitates. ${ }^{25)}$ Thus, the blocks can be identified from the contrast with the martensite base and from the distribution of precipitates.

Figure 9 shows distributions of block widths before and after the test. The mean block widths before and after the test were $1.58 \mu \mathrm{m}$ and $1.62 \mu \mathrm{m}$, respectively, showing similar values. The creep-fatigue test up to rupture did not cause many changes in the size of the block structure (including the packets and prior $\gamma$ grains, which are structural constituents larger than the block scale).

\subsubsection{Subgrains}

As clearly shown in the TEM images in Fig. 4, the subgrain structures differed notably between before and after the creep-fatigue test. Figure 10 shows the distributions of subgrain widths (widths of elliptic subgrains or diameters of equiaxial subgrains) that were measured in four fields of TEM images (same magnification as in Fig. 4) for each before and after the test. The mean subgrain width before the test was $0.45 \mu \mathrm{m}$ and that after the test was $0.93 \mu \mathrm{m}$, showing the subgrains to have almost doubled in size up to creepfatigue rupture. After the test, the subgrains showed greater deviation in size, with coarse subgrains larger than $2 \mu \mathrm{m}$ in width being formed. In consideration of the facts that the mean subgrain width was smaller than the mean block width and that the block width did not change during the test, it is unlikely that subgrains grow to exceed the block boundaries. Block boundaries are high misorientation angle boundaries and are densely covered by precipitates, which may act as barriers to the growth of subgrains. ${ }^{7,26)}$ Therefore, the coarse subgrains of over $2 \mu \mathrm{m}$ in width are likely to have formed within relatively large blocks over $2 \mu \mathrm{m}$ in size.

\subsection{Relationship between microstructure and creep- fatigue property}

Table 2 separately summarizes the measurements of 
(a)

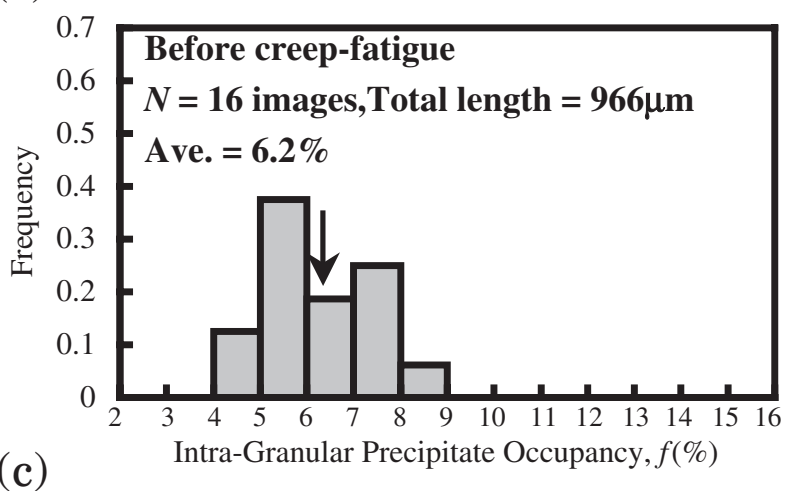

(c)

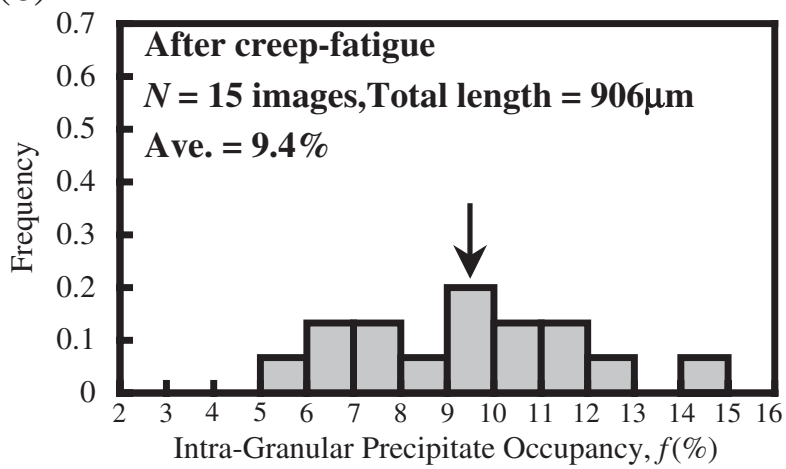

(b)
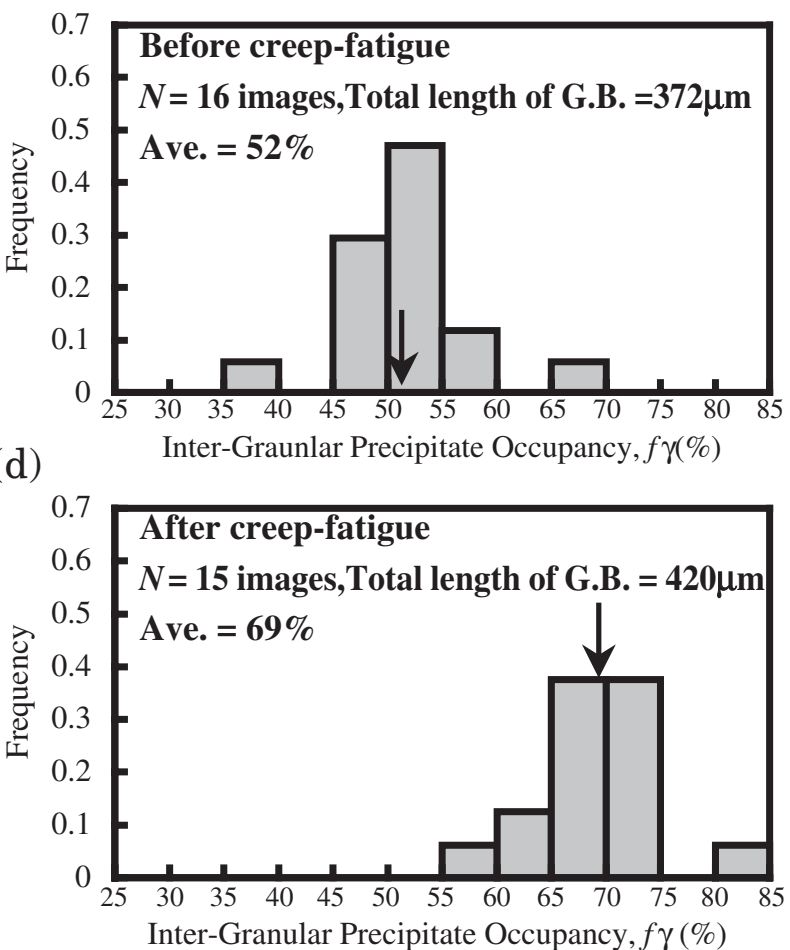

Fig. 6 The frequency of the intra- or inter-granular precipitate occupancy of each of FE-scanning electron image $(\times 5000)$ before and after the creep-fatigue testing, respectively.

(a)

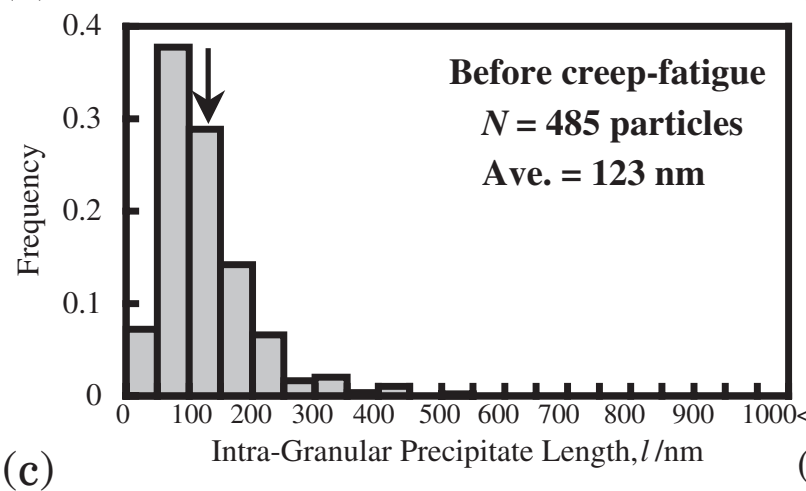

(b)
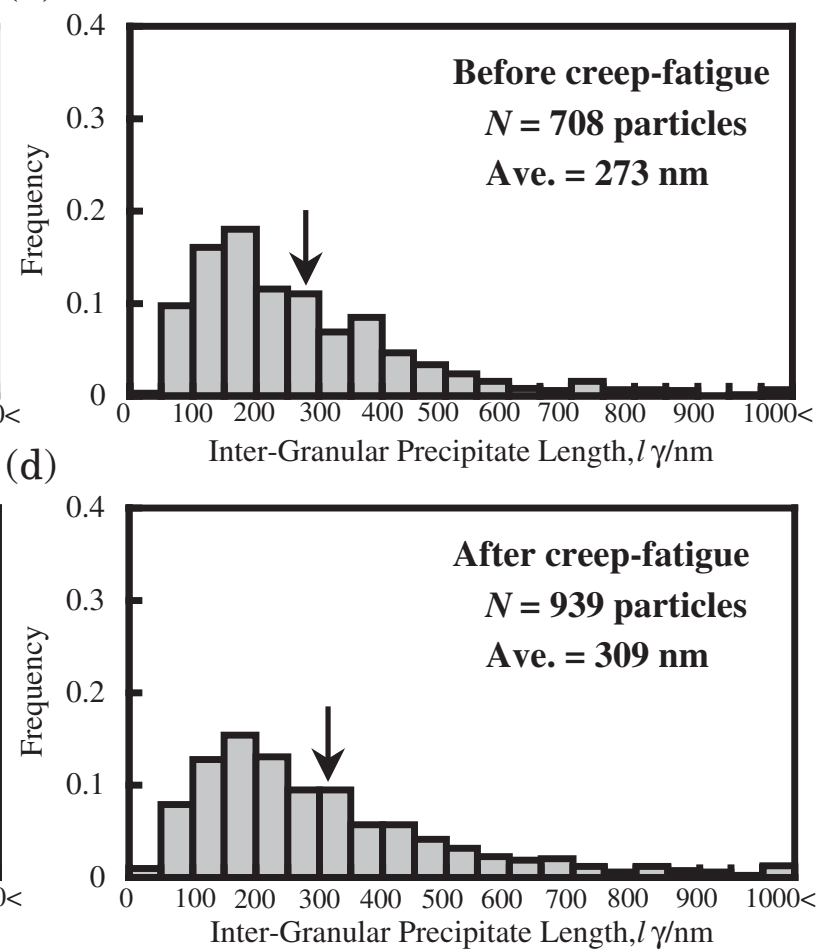

Fig. 7 The frequency of the intra- or inter-granular precipitate length before and after the creep-fatigue testing, respectively.

microstructural constituents within the prior $\gamma$ grains and on the prior $\gamma$ grain boundaries before and after the creep-fatigue test. During the process of creep-fatigue rupture, the block structure showed no changes, whereas marked differences were observed in the precipitate and subgrain structures.

The density of precipitates, especially the occupancy of 


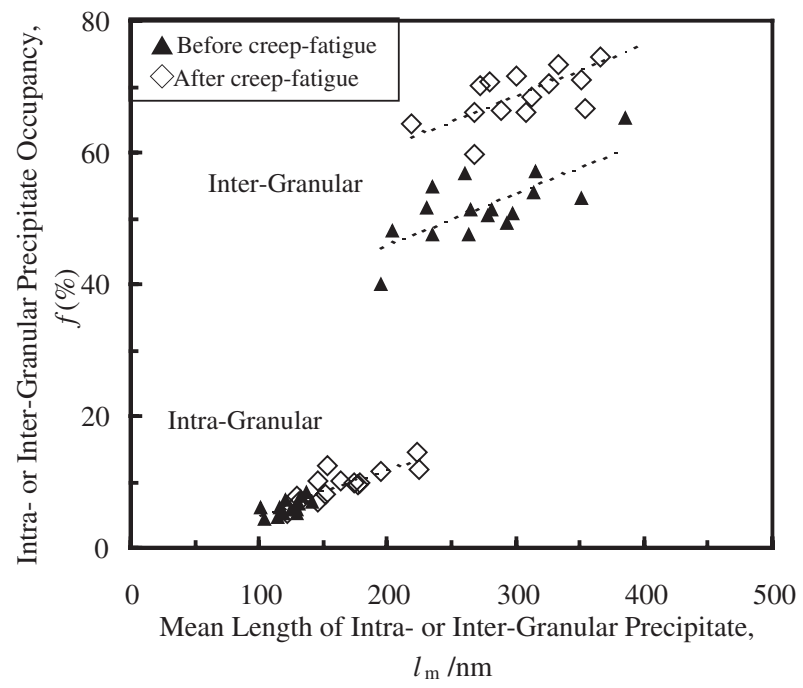

Fig. 8 The relationship between precipitate occupancy and mean length of the intra- or inter-granular precipitate of each of FE-scanning electron image $(\times 5000)$ before and after the creep-fatigue testing, respectively.

(a)

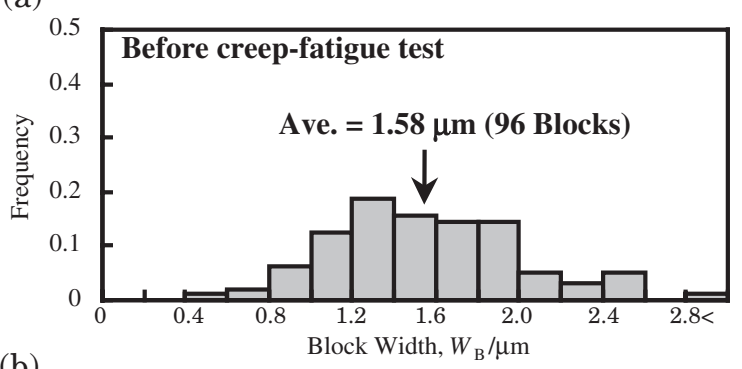

(b)

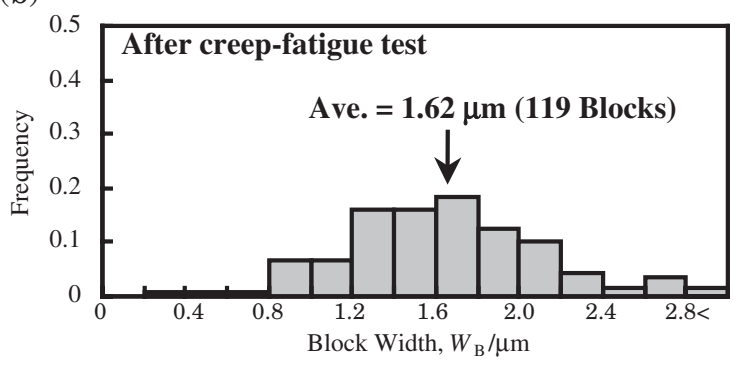

Fig. 9 The frequency of the block size is shown as the function of width. Width were measured in several FE-scanning electron images before and after the creep-fatigue testing in (a) and (b), respectively.

prior $\gamma$ grain boundaries, increased. The main precipitates of high-chromium-tungsten ferritic steel are thought to be $\mathrm{Cr}_{23} \mathrm{C}_{6}$ and $\mathrm{Fe}_{2} \mathrm{~W}$ (Laves phase). ${ }^{27)}$ However, it is difficult to identify precipitates on grain boundaries from FE-SEM images. If the creep-fatigue fractures originated on grain
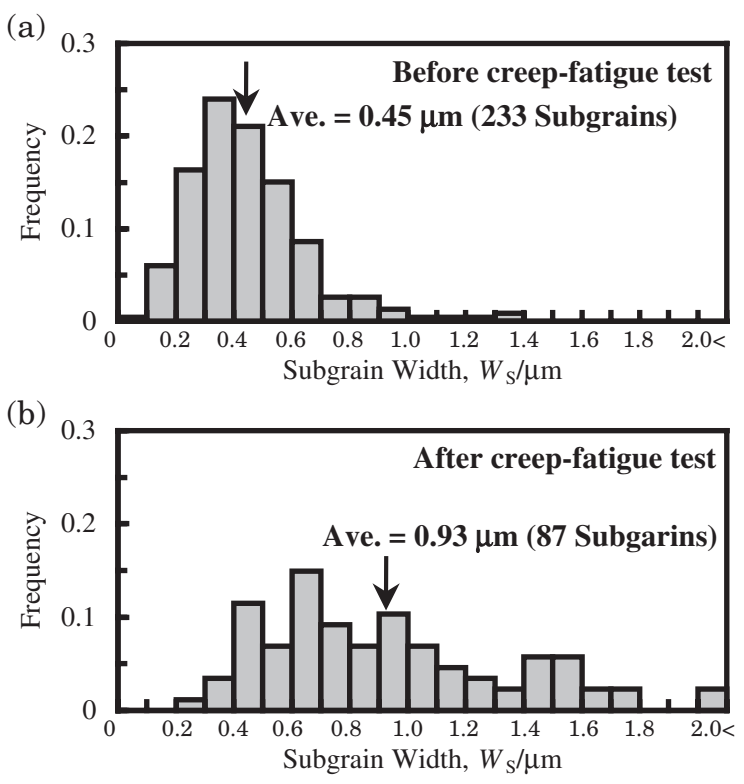

Fig. 10 The frequency of the subgrain size is shown as the function of width. Width were measured in four transmission electron images before and after the creep-fatigue testing in (a) and (b), respectively.

boundaries, increases in precipitate density (or occupancy) may have weakened the bonding force between grains. If this is the case, changes in the occupancy of precipitates on grain boundaries during the creep-fatigue rupture test can be used as a new index to show sensitivity to grain-boundary fracture.

On the other hand, subgrains are structural factors within prior $\gamma$ grains. When there were coarse blocks near prior $\gamma$ grain boundaries, local deformations were concentrated near the boundaries. ${ }^{24)}$ During creep tests, recovery near the prior $\gamma$ grain boundaries progressed prior to recovery in other regions, ${ }^{28)}$ and grown coarse subgrains are considered to accelerate grain boundary rupture. Therefore, if coarse subgrains over $2 \mu \mathrm{m}$ in width are frequently formed near prior $\gamma$ grain boundaries during creep-fatigue tests, they are likely to be implicated in grain boundary fractures. Nonuniform changes in precipitate and subgrain distributions appear to be related to creep-fatigue fractures originating at grain boundaries. However, the positional relationship between these coarse subgrains and prior $\gamma$ grain boundaries could not be determined due to the small visual field of the TEM images. One of our future studies is to identify the distribution of coarse subgrains in multi-scale structures.

\section{Conclusions}

The microstructures of ferritic $12 \mathrm{Cr}-2 \mathrm{~W}$ heat-resisting

Table 2 Summary of the microstructure factors before and after the creep-fatigue testing.

\begin{tabular}{|c|c|c|c|c|c|c|c|}
\hline & \multicolumn{5}{|c|}{ Inner prior austenite grain } & \multicolumn{2}{|c|}{ : Prior austenite grain boundary } \\
\hline & Block & Subgrain & Precipitate & Precipitate & $:$ & Precipitate & Precipitate \\
\hline & Width & Width & length & occupancy & & length & occupancy \\
\hline & $W_{\mathrm{B}} / \mu \mathrm{m}$ & $W_{\mathrm{S}} / \mu \mathrm{m}$ & $l / \mathrm{nm}$ & $f(\%)$ & : & $l_{\gamma} / \mathrm{nm}$ & $f_{\gamma}(\%)$ \\
\hline (a)Before & 1.58 & 0.45 & 123 & 6.2 & : & 273 & 52 \\
\hline (b)After & 1.62 & 0.93 & 166 & 9.4 & : & 309 & 69 \\
\hline
\end{tabular}


steel were observed under FE-SEM and TEM before and after a creep-fatigue test. The sizes and distributions of precipitates, blocks and subgrain structures were characterized based on these results.

Our resultant conclusions are:

(1) An estimation method is proposed to show non-uniform changes in the distribution of precipitates during creepfatigue tests. The method shows that a) occupancy of prior $\gamma$ grain boundaries by precipitates was high in ruptured specimens, and b) changes in distribution of precipitates on the boundaries were non-uniform compared to those in the entire microstructure.

(2) The creep-fatigue test up to rupture causes no change in block size.

(3) The creep-fatigue test causes coarse subgrains with widths of over $2 \mu \mathrm{m}$ to be formed, widening the distribution of subgrain sizes.

(4) Non-uniform changes in precipitate and subgrain distributions, which were observed locally compared to those in the entire microstructure, are suggested to be related to creepfatigue fractures that originate at grain boundaries.

\section{REFERENCES}

1) F. Masuyama: The EPRI/National Power Conference, New Steels for Advanced Plant up to $620^{\circ} \mathrm{C}$, ed. by E. Metcalfe, (Soc. Chem. Indus., London, 1995) pp. 98-108.

2) T. Fujita: Tetsu-to-Hagane 76 (1990) 1053-1075.

3) M. Kimura, K. Kobayashi and K. Yamaguchi: Tetsu-to-Hagane 87 (2001) 508-514.

4) K. Kimura, K. Kobayashi and K. Yamaguchi: J. High Pressure Inst. Japan. 40 (2002) 262-269.

5) M. Kimura, K. Kobayashi and K. Yamaguchi: Mater. Sci. Res. Inter. 9
(2003) 50-54.

6) M. Kimura, K. Yamaguchi, M. Hayakawa and K. Kobayashi: Tetsu-toHagane 90 (2004) 27-32.

7) Y. Hasegawa, M. Ohgami and T. Muraki: J. Soc. Mat. Sci. Japan 52 (2003) 843-850

8) S. Ohta: Ferritic Heat-Resisting Steels, (Chijin Shokan Co., Ltd., Tokyo, 1998) pp. 218-245.

9) F. Masuyama: ISIJ Inter. 41 (2001) 612-625.

10) K. Maruyama, K. Sawada and J. Koike: ISIJ Inter. 41 (2001) 641-653.

11) Y. Kadoya and E. Shimizu: Tetsu-to-Hagane 88 (2002) 539-546.

12) M. Hayakawa, T. Hara, S. Matsuoka and K. Tsuzaki: J. Japan Inst. Metals 64 (2000) 460.

13) M. Hayakawa, S. Matsuoka and K. Tsuzaki: J. Japan Inst. Metals 65 (2001) 741-748.

14) M. Hayakawa, S. Terasaki, T. Hara, K. Tsuzaki and S. Matsuoka: J. Japan Inst. Metals 66 (2002) 745-753.

15) M. Hayakawa, S. Matsuoka, K. Tsuzaki, H. Hanada and M. Sugisaki: Scr. Mater. 47 (2003) 655-661.

16) A. R. Marder and G. Krauss: Trans. ASM 60 (1967) 651-660.

17) T. Maki, K. Tsuzaki and I. Tamura: Trans. ISIJ 20 (1980) 207-214.

18) T. Maki and I. Tamura: Tetsu-to-Hagane 67 (1981) 852-866.

19) R. M. Horn and R. O. Ritchie: Metall. Trans. A 9A (1978) 1039-1053.

20) G. Krauss and C. J. McMahon Jr.: Martensite, eds. by G. B. Olson and W. S. Owen, (ASM International, New York, 1992) pp. 295-321.

21) F. Nakasato and F. Terasaki: Tetsu-to-Hagane: 61 (1975) 856-868.

22) ASTM Designation E112-82, 1983 Annual Book of ASTM Standards 03.03 (1983) pp. 121-155.

23) H. Hirukawa, S. Matusoka, Y. Furuya and K. Miyahara: Trans. Japan Soc. Mech. Engrs. 68 (2002) 1473-1480.

24) M. Hayakawa, S. Matsuoka and Y. Furuya: J. Japan Inst. Metals 67 (2003) 354-361.

$25)$ B. S. Lement, B. L. Averbach and M. Cohen: Trans. ASM. 47 (1955) 291-320.

26) T. Nishizawa: Tetsu-to-Hagne 70 (1984) 1984-1992.

27) F. Abe, H. Araki and T. Noda: Metall. Trans. A 22A (1991) 2225-2235.

28) K. Kimura, T. Matsuo, M. Kikuchi and R. Tanaka: Tetsu-to-Hagane 72 (1986) 474-481. 